\title{
An empirical study on human resource competencies and its relationship with productivity
}

\author{
Hasan Darvish, Alireza Moogali, Mohammad Moosavi and Belal panahi*
}

Faculty Member, Department of management, Payam Noor University, PO BOX 19395-3697, Tehran, Iran

\begin{tabular}{|c|c|}
\hline AR T I C L E I N F O & A B S T R A C T \\
\hline $\begin{array}{l}\text { Article history: } \\
\text { Received April 20, } 2012 \\
\text { Received in Revised form } \\
\text { June, } 12,2012 \\
\text { Accepted } 29 \text { June } 2012 \\
\text { Available online } \\
\text { July } 12012 \\
\text { Keywords: } \\
\text { Credible activist } \\
\text { Culture \& change steward }\end{array}$ & $\begin{array}{l}\text { This study evaluates the impact of human resource competencies on productivity. The proposed } \\
\text { study considers different issues such as different competencies associated with human } \\
\text { resources, how we can persuade and strengthen such competencies in organizations and } \\
\text { whether human resource competencies impact organizational productivity or not. There are one } \\
\text { main hypothesis six minor hypotheses in this study. The proposed study uses descriptive and } \\
\text { regression technique to perform the study. The population of this study includes all managers } \\
\text { who work for an Iranian petroleum company. This result of this survey shows that that human } \\
\text { resource competencies impact organizational productivity. In addition, all dimensions of } \\
\text { human resource competencies had significant relationship on organizational productivity. }\end{array}$ \\
\hline
\end{tabular}

C 2012 Growing Science Ltd. All rights reserved.

\section{Introduction}

Today's successful managers believe that the valuable assets creating competitive advantage for organizations are their staffs and only human capitals keep them as a pioneer in competition. Organizations have been awarded from emerging and potential abilities of human resource strategies, and it grows the role of intangible assets and intellectual capital in the competitive global. (Becker et al., 2001) In this regard, human resources (HR) need to introduce new functions and policies, so that human resources prepare policies, and personnel implement them. According to Purcell et al. (2003) operational managers implement human resource policies and in case they do not accept what human resources expect from them, there will be a conflict of interest and they may not accomplish their task, properly and there are some negative consequences (Armstrong, 2006). In addition, Quinn (1980) argued that distinctive capabilities or competencies of a company could create many various consequences.

* Corresponding author. Tel: +989141772530

E-mail addresses: panahi1980@yahoo.com (B. Panahi) 
Competencies are not only important for employment but also they are important in numerous functions of human resources. All sorts of competencies, which are well-defined can be taught, learned, measured and monitored and they can be considered as early signs of achieving individuals' performance. They can be used to accommodate a person with specific occupation, diverse human resources activities, and measure of the performance and added value for customers (Ulrich et al., 2008).

Any company wishing to consolidate its positions in the industry must figure out whether the use of existing facilities can perform the necessary activities better than competitors, or to achieve desired goals the company should take some necessary activities. Thus, companies with consolidated position within industry have competitive advantages compared with others. Companies with no strong position in the industry often confront with serious problems in competing with other companies and cannot earn through competitive advantage (Khorasani et al., 2007). To maintain and track changes in the duties and functions of human resources, HR professionals must develop and define a new set of competencies for completing their changing roles and responsibilities (Yeung, et al., 1996). New economic paradigm requires some HR professionals to do different things than they did in the past. This is beyond some certain strategies of companies. Therefore, HR professionals must obtain new competencies for doing effectively their new and strategic roles. They also dominate on the HR knowledge derived normally through research and education (Sang Long, 2008).

Competencies imply on knowledge, skills, abilities or personality characteristics that have a direct effect on job performance. The concept of individual competency has a long history in management and in the past, its focused was more on leaders and top managers (Becker et al., 2001). The base of many abilities, skills and knowledge of employees of a company is often rooted in its functional specialization (Khorasani et al., 2007). Competencies are used in many aspects of human resources, which include a range of individual actions such as recruiting and performance management to strategic planning and organizational design, management of organizational structure and culture (Sang Long, 2009). Being a strategic partner requires that HR professionals exactly know which competency ensures the successful implementation of corporate strategy and how human resources affect these competencies. This is a serious matter, because from the perspective of traditional roles, HR professionals are not more than official or functional workers (Becker et al., 2001). Barney (1991) introduced four criteria to decide whether a resource is distinguished as competency or not and they include the value created for customers, being exclusive compared with others, impossible for duplication and no possibility for an alternative one (Armstrong, 2006).

Prahalad and Hamel (1990) stated that a company or organization will have long-term competitive advantage that have "core competencies" and theses competencies are better than other competitors (Armstrong, 2006). Distinctive capabilities or core competencies indicates that an organization is expertise or unique in doing things, and at the same time, it does better than others or its competitors. Core capabilities normally exist in specific areas such as technology, innovation, marketing, quality and appropriate utilization of human and financial resources. Thus, if an organization is aware of its distinctive capabilities, it can focus on exploiting them and developing them, without wasting energy on inefficient activities. According to researchers, we can claim that the distinctive features include the knowledge, skills, expertise and commitment of staff. These concepts are basic for strategic HRs management and HRs competencies (Armstrong, 2006).

\section{New HR competencies as the framework of this research}

According to Ulrich's latest research (2007), HR professionals must play an important role in six important areas. According to this model, In addition to a HR profession for being operational executor also he/she should be a good credible activist, culture \& change steward, talent manager /organization designer, architecture and allied business strategy. A HR profession must have 
individual credibility and he/she gains strategic, business and organizational competencies until he/she could develop his/her strategic position. The determination and recognition of individual, managerial and organizational competencies is an inevitable necessary for various levels in organizations. Human resources professionals must identify necessary competencies as a leader in value creation, and they learn and apply them in practice (Ulrich et al., 1997).

The six domains of core competency that HR professionals need to gain them show that the evolution and improvement of human resources play an important role in today's business market. While in the past, the focus was more on the area of business-related knowledge, human resources need to have knowledge of their own business. Today, expectations from the human resources have changed so that they are expected to play more important role on business ally. Therefore, human resources must be a strategic partner and they are necessary to know, but more importantly, they know what they need.

\subsection{Credible activist}

Human resources must be both credible, the person who is respected and admired, and activist, who offers new ideas and challenges the existing assumptions. Some people called this aspect as a "HR expert ". Any human resources who are credible but not activist may be admired but not so effective. Activists who are not credible have ideas that one does not run it (Ulrich et al., 2008). HR professionals need to be credible people for both their colleagues in human resources area and for operational managers in other areas. They must do their promises and to put credible indications from themselves (Sang Long, 2008). Ulrich discovered four factors associated with this area, including the ability to offer achievements honesty, to share information, to build relationships based on trust and to carry out human resources activities thoughtfully (Ulrich et al., 2008).

\subsection{Culture \&Change Steward}

HR knows how important the company culture is and they help in shaping it. Culture is a pattern of activity over the concept of a single event (Ulrich et al., 1996). Human resources as a culture \& change steward are expected to respect the past aspects of culture and at the same time form a new culture where it could help them facilitate the organizational success. They guide organizations with their actions. Human resources professionals facilitate this in two ways: First, they help to develop right culture in the organization. Second, they develop the systems to encourage changes throughout the organization. Ulrich discovered four factors associated with this area including guiding the culture, facilitating the change, individualization of culture and applying the culture (Ulrich et al., 2008).

\subsection{Talent Manager / Organizational Designer}

Human resource professionals in this role direct theory, research and action in both talent management and organizational design areas. Talent management focuses on requirements of necessary competencies. On the other, hand organizational design focuses on how a company relates its capabilities to the structure, processes and policies. HR professionals must be ensuring that tools of talent management and organization's capabilities are aligned with customer's requirements and organizational strategy. Therefore, good talent will not be viable and stable without the support of organization; and a good organization will not reach its achievements for presentation without talented people (Ulrich et al., 2008).

\subsection{Strategy architect}

HR professionals have a vision on how the organization can be a winner in future competitive market. They play active role in developing an overall strategy for doing their visions. This means considering the business trends and its impact on business processes, they need to anticipate potential 
obstacles on their way to success and to facilitate the process of strategies transparent. In addition, human resources are contributing in creating the overall strategy through linking the internal organization to the external customer expectations. This link helps the customer-centric business strategies for their employees really (Ulrich et al., 2008). Ulrich (1997) found that there were two major barriers keeping HR professional from being a strategic partner, which are "no time to address both administrative and strategic issues" and "lack of knowledge and competencies". Ulrich's analysis revealed two distinct operating in Strategy architect area: To strengthen the strategic agility and customers' participation (Ulrich et al., 2008).

\subsection{Operational executor}

Human resources are implementing the operational aspects of people and organization management and zolicies should be directed and be compatible. In addition, employees have many administrative needs (e.g., payment, transport, employment \& training). HR professionals are confident that the basic needs of human resources are to use proper technology, shared services and outsourcing as effectively (Ulrich et al., 2008) and these items increase the ability of human resources in doing operational aspect of managing people and organization. Activities such as policy administration, compliance and enforcement are at the center of this area. In addition, it is necessary to focus on pay, employment and training the employees. Human resources are required to ensure from effective responsibility the basic needs.

\subsection{Business ally}

Success in business will be achieved with the appropriate goal setting relying on external opportunities and threats. Human resources contribute to business success through understanding the social context or environment in which business does it. They also must know how to gain income, value chain characteristics in business and customers' specifications. Finally, they have a good understanding of different business sectors such as finance, marketing, R \& D and engineering, how they work and how they work together; so they could help their business to achieve profit. Human resources are expected to involve in business success, directly and this is obtained by giving an appropriate response to changing external conditions (Ulrich et al., 2008). Human resources specialists are expected to help compete for their business and in this way human resources should not only be observed but it is necessary to understand new business trends and adapt with them (Sang Long, 2009).

\subsection{Human resources and its impact on productivity}

Productivity in many organizations is one of the key issues in business where its impact on all organizational matters could be the origin of movement and change in organizations. Human resources are the main factor for improving productivity. The fundamental default about performance of human resources management is that human resources are primary and main source in organization and organizational performance will mainly depend on them (Armstrong, 2006). Although most managers do not recognize the real value of human resources, human resources have the potential to increase profit without reducing costs.

\subsection{The balanced scorecard approach and review the productivity}

A review of existing approaches in the field of human resource productivity determines that, first there is not a comprehensive theory that encompasses all aspects of productivity. Second, there are obvious similarities in various theories and existing approaches have many common features than different features do. Organizations and human resource management units are open systems. These systems are affected from the environment in which they are working, and on the other hand, affect their environment. Some of the challenges have limited effects on firms or the industry, but many environmental challenges largely affect their human resources departments. External environment can influence firm's human resources from outside of organization while, the internal environment affects 
human resources within the boundaries of the organization. In addition, personnel specialists are working continually with other people in other fields of specialization such as marketing, production, and financial. Therefore, they should understand different intellectual aspects of people in various fields until they could do their duties favorably.

Kaplan and Norton (1992), in order to determine an appropriate process planning and performance control, developed the idea of balanced scorecard (BSC) for the business. BSC reflects the changing nature of technology and competitive advantage in the new century (Kaplan \& Norton, 1996). Kaplan and Norton's scorecard model is an excellent example of approach that makes integrated and coherent the human resource management with overall strategy of institution. This model refers to the major perspectives: Financial perspective (financial consequences and values associated with partners) that is a priority of institute strategy; customer perspective (relationship with satisfaction customer); and internal view (in relation to internal operations) and the learning and growth perspective. Kaplan and Norton indicated that improvement in four dimensions may lead to an increase in profits (Kaplan \& Norton, 1992).

BSC emphasizes the linkage of measurement to strategy (Kaplan \& Norton, 1993). Strategies related to learning and growth perspective are necessary to the previous perspective and deals with issues of human resources. Thus, strategic human resource management is essential for effective internal operations and this will enhance the customer satisfaction. In other words, SHRM is considered as the first ring in chain leading to achieve the desired targeted financial outcomes by the strategy of business (Amiri \& Panahi, 2010). Thus, as discussed by Hendry and Pettigrew (1986), human resources within a firm are an important strategic resource for achieving and sustaining competitive advantage, and even it can be considered as a tool and weapon that are located in the hands of a talented strategist of human resource management (Boxall \& Purcell, 2003). Basic supposition of BSC is that senior managers used to spend too much attention to financial aspects of performance and insufficient attention to the forces that make the results. In general, financial measures essentially are after action, while management can control the performance drivers. BSC system encourages managers to intervene in the process of strategy implementation effectively.

\section{Hypothesis and Conceptual model}

Based on theoretical and background discussions, the following hypotheses are investigated.

The main hypothesis: Human resources competencies have significant effect on productivity.

Hypothesis 1: Credible Activist has an impact on productivity.

Hypothesis 2: Culture \&Change Steward has an impact on productivity.

Hypothesis 3: Talent Manager / Organizational Designer have impact productivity.

Hypothesis 4: Strategy architect has an impact on productivity.

Hypothesis 5: Operational executor has an impact on productivity.

Hypothesis 6: Business ally has an impact on productivity. 


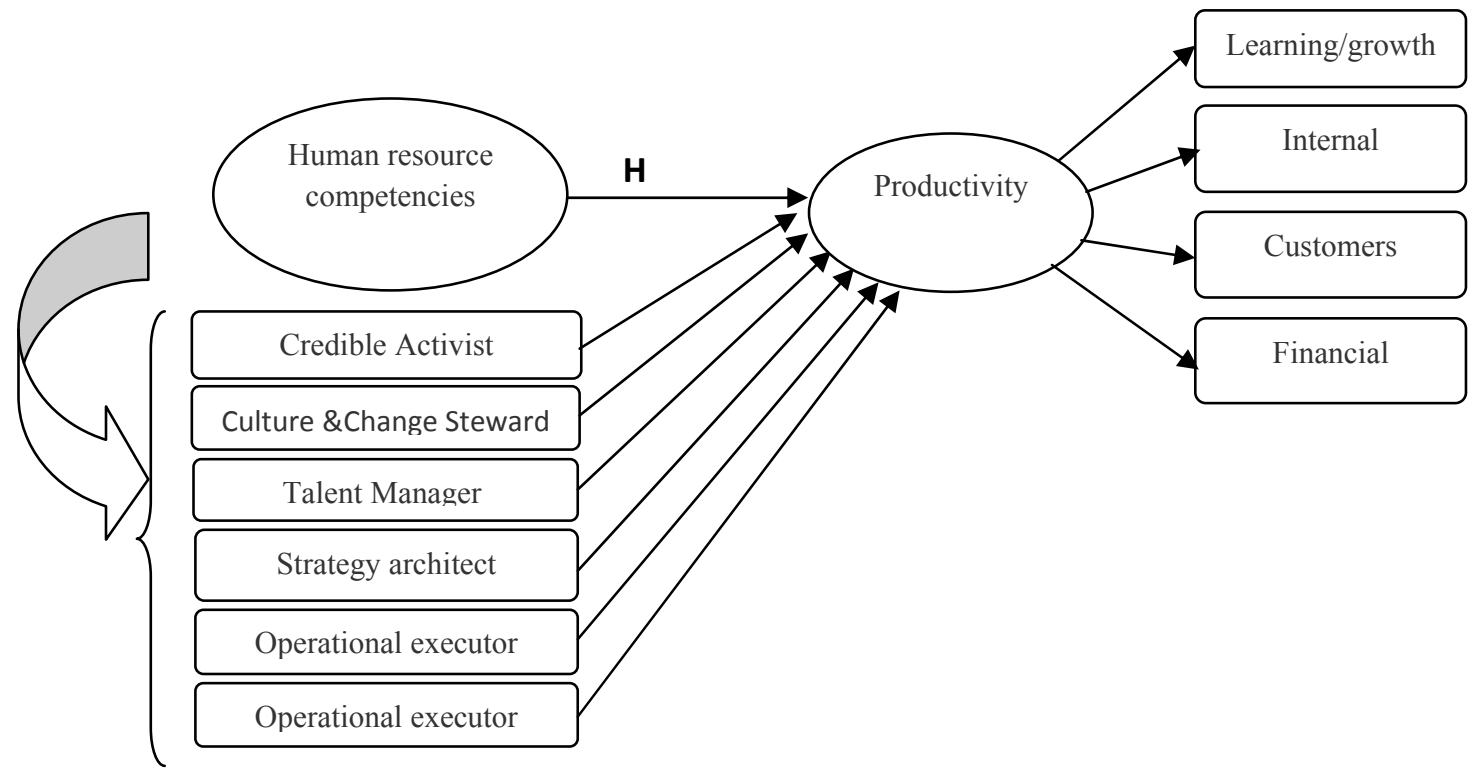

Fig. 1. Conceptual model

\section{Methodology}

\subsection{Sample and procedure}

Research method and sample of this survey is based on descriptive goal. The population includes 336 managers who work for an Iranian petroleum company and the proposed model selects 218 people, randomly based on Kokran formula.

\subsection{Measures}

The used tool to gather data is a questionnaire, which is divided into two parts. The first part is related to the human resources competencies, which includes 60 questions: Credible Activist (10 items), Culture \& Change Steward(12 items), Talent Manager / Organizational Designer(9 items), Strategy $\operatorname{architect}(7$ items), Operational executor(9 items), Business ally(13 items).); and the second one to examine productivity includes 20 questions: financial aspect(4 items), customers aspect(4 items), internal aspect( 8 items), and learning/growth aspect(4 items) and it has been regulated due to the liker's spectrum (Completely disagree, disagree, senseless, agree, and completely agree). In this regard, the Ulrich' indicators (2008) were used to measure the human resources competencies; so to measure productivity we have used BSC model. Chronbach alpha was used to survey the reliability and confirmatory factor analysis (CFA) was used to survey the Validity. Table 1 shows Cronbach alpha for all constructs. The data was analyzed by use of correlate and regression test, structural equations.

\section{Table 1}

Results of reliability tests on constructs

\begin{tabular}{lcc}
\hline Variables & Items & Cronbach alpha \\
\hline Credible Activist & 10 & 0.976 \\
Culture \& Change Steward & 12 & 0.975 \\
Talent Manager / Organizational Designer & 9 & 0.964 \\
Strategy architect & 7 & 0.921 \\
Operational executor & 9 & 0.968 \\
Business ally & 13 & 0.960 \\
Learning/growth aspect & 4 & 0.918 \\
Customers aspect & 4 & 0.892 \\
Internal aspect & 8 & 0.95 \\
Fnancial aspect & 4 & 0.905 \\
\hline
\end{tabular}




\section{Data analysis}

Table 2 shows the results of the implementation of multiple regression test associated with the dimensions of human resource competencies and its impact on productivity.

Table 2

Results of regression test

\begin{tabular}{|c|c|c|c|c|c|c|c|}
\hline $\begin{array}{l}\text { Dependent } \\
\text { variable }\end{array}$ & $\begin{array}{l}\text { Dimensions of Human resource competencies } \\
\text { (Independent variables) }\end{array}$ & Sig & $\mathrm{T}$ & Beta & $\begin{array}{l}\text { Std. } \\
\text { Error }\end{array}$ & B & $\mathrm{R}^{2}$ \\
\hline \multirow{6}{*}{$\begin{array}{l}\overrightarrow{0} \\
\stackrel{0}{0} \\
\stackrel{0}{\Xi} \\
\text { ¿. }\end{array}$} & Credible Activist $\left(\mathrm{x}_{1}\right)$ & .009 & 2.630 & .226 & .072 & .191 & \multirow{6}{*}{$.88 \mathrm{c}$} \\
\hline & Culture \&Change Steward $\left(\mathrm{x}_{2}\right)$ & .047 & 1.999 & 151 & .067 & .133 & \\
\hline & Talent Manager / Organizational Designer $\left(\mathrm{x}_{3}\right)$ & .001 & 3.393 & .256 & .067 & .226 & \\
\hline & Strategy $\operatorname{architect}\left(\mathrm{x}_{4}\right)$ & .062 & 1.879 & .077 & .043 & .081 & \\
\hline & Operational executor $\left(\mathrm{x}_{5}\right)$ & .020 & 2.338 & 166 & .061 & .142 & \\
\hline & Business ally $\left(\mathrm{x}_{6}\right)$ & .010 & 2.608 & .121 & .046 & .119 & \\
\hline
\end{tabular}

As we can observe from the results of Table 2, that there is a positive correlation among all variables and dependent variable. Therefore, the equation for this regression test is as follow,

$\mathrm{Y}=0.405+0.226 \mathrm{x}_{1}+0.151 \mathrm{x}_{2}+0.256 \mathrm{x}_{3}+0.077 \mathrm{x}_{4}+0.166 \mathrm{x}_{5}+0.121 \mathrm{x}_{6}+\mathrm{e}$

The results also show that the strategy architect has the lowest impact on productivity and talent manager /organizational designer has the highest impact on productivity.

\subsection{Results of Simple regression test related to the hypotheses}

\section{Hypothesis 1: Credible Activist has an impact on productivity}

\section{Table 3}

The results of regression test related to the effect of Credible Activist on productivity

\begin{tabular}{llllllll}
\hline Independent variable & Dependent variable & R & R2 & B & Beta & T & Sign \\
\hline Credible Activist & Productivity & .918 & .842 & 0.775 & .918 & 33.972 & .000 \\
\hline
\end{tabular}

As we can observe from the results of Table 3, there is a strong positive correlation between the credible activist and productivity. Therefore, because $\mathrm{p}=0.000<0.05, \mathrm{H}_{1}$ is accepted and because Beta $=0.918$, the Credible Activist has an important impact on productivity.

\section{Hypothesis 2: Culture \&Change Steward has an impact on productivity}

\section{Table 4}

The results of regression test related to the effect of Culture \&Change Steward on productivity

\begin{tabular}{llllllll}
\hline Independent variable & Dependent variable & R & R2 & B & Beta & T & Sign \\
\hline Culture \&Change Steward & Productivity & .908 & .824 & 0.805 & .908 & 31.813 & .000 \\
\hline
\end{tabular}

As illustrated in Table 4, there is a positive correlation between culture \& change steward and productivity. Therefore, because $p=0.000<0.05$, the second hypothesis is confirmed. Moreover, the culture \& change steward has an impact on productivity because Beta $=0.908$.

\section{Hypothesis 3: Talent Manager / Organizational Designer have impact on productivity}

\section{Table 5}

The results of regression test related to the effect of Talent Manager/Organizational Designer on productivity

\begin{tabular}{llllllll}
\hline Independent variable & Dependent variable & R & R2 & B & Beta & T & Sign \\
\hline Talent Manager & Productivity & .917 & .840 & 0.810 & .917 & 33.735 & .000 \\
\hline
\end{tabular}


As seen from the results of Table 5, there is a strong positive correlation between the Talent Manager/Organizational Designer and productivity. Therefore, because $p=0.000<0.05$, the hypothesis is confirmed and because Beta $=0 / 917$, the talent manager/organizational designer has an impact on productivity.

\section{Hypothesis 4: Strategy architect has an impact on productivity}

\section{Table 6}

The results of regression test related to the effect of Strategy architect on productivity

\begin{tabular}{llllllll}
\hline Independent variable & Dependent variable & R & R2 & B & Beta & T & Sign \\
\hline Strategy architect & Productivity & .790 & .625 & 0.833 & .790 & 18.963 & .000 \\
\hline
\end{tabular}

As shown in Table 6, there is a strong positive correlation between the credible activist and productivity. Therefore, because $\mathrm{p}=0.000<0.05$, the hypothesis is accepted and because Beta $=0.790$, the strategy architect has an impact on productivity.

\section{Hypothesis 5: Operational executor has an impact on productivity}

\section{Table 7}

The results of regression test related to the effect of Operational executor on productivity

\begin{tabular}{llllllll}
\hline Independent variable & Dependent variable & $\mathrm{R}$ & $\mathrm{R}^{2}$ & $\mathrm{~B}$ & $\mathrm{Beta}$ & $\mathrm{T}$ & Sign \\
\hline Operational executor & Productivity & .903 & .815 & 0.770 & .903 & 30.847 & .000 \\
\hline
\end{tabular}

As seen from the results of Table 7 , there is a strong positive correlation between the operational executor and productivity. Therefore, because P-value $=0.000<0.05$, the hypothesis is confirmed and because Beta $=0.903$, the Operational executor has an impact on productivity.

\section{Hypothesis 6: Business ally has an impact on productivity}

\section{Table 8}

The results of regression test related to the effect of Business ally on productivity

\begin{tabular}{llllllll}
\hline Independent variable & Dependent variable & $\mathrm{R}$ & $\mathrm{R}^{2}$ & $\mathrm{~B}$ & $\mathrm{Beta}$ & $\mathrm{T}$ & $\mathrm{Sign}$ \\
\hline Business ally & Productivity & .827 & .685 & 0.815 & .827 & 21.653 & .000 \\
\hline
\end{tabular}

As seen from the results of Table 8, there is a strong positive correlation between the Business ally and productivity. Therefore, because $\mathrm{p}=0.000<0.05$, the hypothesis is confirmed and because Beta $=$ $0 / 827$, the Business ally has an impact on productivity.

\section{The main Hypothesis: Human resources competencies have significant effect on productivity.}

\section{Table 9}

The results of regression test related to the effect of Human resources competencies on productivity

\begin{tabular}{llllllll}
\hline Independent variable & Dependent variable & R & R2 & B & Beta & T & Sign
\end{tabular}

\begin{tabular}{llllllll}
\hline Human resources competencies & Productivity & .904 & .818 & 0.876 & .904 & 31.143 & .000
\end{tabular}

As shown in Table 9, there is a strong positive correlation between the Human resources competencies and productivity. Therefore, because $p=0.000<0.05$, the hypothesis is confirmed and because Beta $=0.904$, the Human resources competencies has an impact on productivity.

\subsection{Friedman Test}

The Friedman Test is used in order to survey the relative importance of human resource competencies dimensions. The result of this test is shown in Table 10, that all dimensions have similar importance $(p$-value $=0 / 141)$. 
Table 10

The results of Friedman Test

\begin{tabular}{llll}
\hline Dimensions of Human resource competencies & Mean Rank & Chi-Square & Asymp. Sig. \\
\hline Credible Activist & 3.41 & & \\
Culture \&Change Steward & 3.35 & & \\
Talent Manager / Organizational Designer & 3.32 & 8.280 & .141 \\
Strategy architect & 3.64 & & 5 \\
Operational executor & 3.69 & & \\
Business ally & 3.61 & & \\
\hline
\end{tabular}

\section{Conclusions}

In this paper, we have performed an empirical analysis for influencing factors on human resource competencies and its relationship with organizational productivity. The proposed study studied human resource competencies in six categories based on a method developed by Ulrich (2007). These categories of human resource competencies were Credible Activist, Culture \&Change Steward, Talent Manager/Organizational Designer, Strategy architect, Operational executor, Business ally. Based on the results of this survey, productivity was measured on four dimensions of BSC method. In summary, this study offered several notable conclusions: the human resource competencies depend on six mentioned factors, all of them played important role in organizational performance, and productivity. However, the factors of Talent Manager/Organizational Designer and Credible Activist maintained the maximum effects on productivity. Therefore, According to the findings, all hypotheses were accepted. In addition, data analysis shows that human resources' competencies have significant effect on productivity. The results are consistent with the results of previous surveys (Lee et al 2010; Barney 1991; Sang Long 2008, 2009; Ulrich et al., 2008, etc.).

\section{References}

Amiri, A.N., \& Panahi, B. (2010), International Human resource management: Theory and Practice; Samt Publications. [In Persian].

Armstrong, M. (2006). Strategic Human Resource Management: A Guide to action. Kogan Publications.

Bamberger, P \& Meshoulam, I. (2000). Formulation, Implementation and Impact of Human Resource Strategy. SAGE Publications.

Becker E. B., Huselid, A. M., \& Ulrich, D. (2001). The HR Scorecard: Linking People, Strategy and Performance. Harvard Business School Press.

Barney, J. (1991). Firm resources and sustained competitive advantage. Journal of Management, 17(1), 99-120.

Barney, J. (2001). Is the resource-based view a useful perspective for strategic management research? Yes. Academy of Management Review, 26(1), 41-56.

Boxall, P., \& Purcell, J. (2003). Strategy and Human Resource Management. New York: Palgrave Macmillan.

Hendry, C., \& Pettigrew, A. (1986). The Practice of Strategic Human Resource Management. Personnel Review, 15(5), 3-8.

Kaplan, R. S., \& Norton, D. P. (1992). The balanced scorecard - measures that drive performance. Harvard Business Review, 70(1), 71-79.

Kaplan, R. S., \& Norton, D. P. (1993). Putting the balanced scorecard to work. Harvard Business Review, 71(5), 134-142.

Kaplan, R. S., \& Norton, D. P. (1996). Linking the balanced scorecard to strategy. California Management Review, 39(1), 53-79.

Khorasani, M., Kardar, S., Kardar, J., \& Kholgi, A. (2007). Strategic management: Competitive and Globalization, Jangle Publications [In Persian]. 
Lee, F.H., Lee, T.Z., \& Wu, W.Y. (2010). The relationship between human resource management practices, business strategy and firm performance: evidence from steel industry in Taiwan. The International Journal of Human Resource Management, 21(9), 1351-1372.

Prahalad, C.K., \& Hamel, G. (1990). The core competence of the corporation, Harvard Business Review, 68(3), 79-91.

Choi, S.L. (2008). Examining human resource competencies and their relationship to the success factors of HR profession. Journal of Service Science and Management, 1, 259-265.

Choi, S.L. (2009). The effect of the demographic factors on the competency of HR practitioners in Malaysia. European Journal of Social Sciences, 12(1), 21-30.

Stewart L. Greg \& Brown G. (2008). Kenneth Human Resource Management: Linking Strategy to Practice. John Wiley \& Sons Publications.

Quinn, J.B. (1980). Strategies for Change: Logical Incrementalism. Richard D Irwin, Homewood: ICC.

Ulrich. D., Brockbank,W., Johnson, D., Sandholtz, K. \& Younger, J. (2008). HR Competencies: Mastery at the Intersection of People and Business. The RBL Institute, the Society for HRM.

Ulrich,D., Brockbank, W., Johnson, D., \& Younger, J. (2007). Human resource competencies: Responding to increased expectations. Employment Relations Today, 34 (3), 1-12.

Ulrich, D. (1997). HR of the future: Conclusions and observations. HR Management, 36(1), 175-179.

Ulrich, D., Brockbank, D., Yeung, W., Lake, A. K., \& Dale, G. (1995). Human resource competencies; An empirical assessment. Human Resource Management, 34(4), 473-496.

Ulrich, D. (1996). Human Resource Champions: The Next Agenda for Adding Value and Delivering Results. Harvard Business Press.

Yeung, A., Woolcock, P., \& Sullivan, J. (1996). Identifying and developing HR competencies for the future, the California strategic human resource partnership. Human Resource Planning. 19(4), 4858. 